\title{
PENGEMBANGAN MASYARAKAT ISLAM: PROGRAM MAGRIB MENGAJI KECAMATAN KOTO TANGAH PADANG, SUMATERA BARAT
}

\author{
Fadjri Wahyu \\ Universitas Muhammadiyah Sumatera Barat \\ e-mail: djwahyu@gmail.com
}

\begin{abstract}
This study aims to describe the implementation of magical recitation at the Alqur'an Rabbani foundation. Islamic society is a community that lives according to Islamic law. The Maghrib Mengaji Community Movement in Koto Tangah District in the last 3 years has not been effective. The availability of teaching staff and community participation in the Pengaji Maghrib Community Movement is one of the causes of the ineffectiveness of the implementation of the Maghrib Mengaji Community Movement. The purpose of the Maghrib Mengaji Community Movement activates Muslims to learn and read the Koran at sunset and make the religious community accustomed to reading the Qur'an and having a strong religious character in Koto Tangah District. From the results of the research analysis it can be concluded that the Maghrib Mengaji Community Movement is categorized as unsuccessful. This can be seen from the failure to achieve the desired goals and objectives, such as activating tahfiz houses and directing Muslims to study and read the Koran at maghrib and make religious and accustomed people to read Al-Quran and have strong religious character in Koto Tangah District. Factors that influence the success of the policy are found, namely: the availability of teaching staff and community participation.
\end{abstract}

Kata kunci: Pengembangan Masyarakat Islam, Magrib Mengaji

\section{PENDAHULUAN}

$M$ engaji merupakan salah satu aktifitas ibadah yang sangat lekat dengan masyarakat muslim di Indonesia sejak mula berkembangnya islam. sejumlah rumah ibadah seperti surau, mushalla, langgar, mesjid dan lain-lain senantiasa diramaikan dengan kegiatan mengaji, khususnya di waktu sore usai shalat asar maupun ba'da magrib. bagi kaum muslim di Indonesia mengaji tak ubahnya menjadi lembaga pendidikan keagamaan non formal bagi semua anak didik.

Gerakan Masyarakat Maghrib Mengaji atau yang lebih dikenal dengan GEMMAR Mengaji merupakan program nasional Kementerian Agama Republik Indonesia yang dicanangkan di tiap Propinsi dan Kabupaten/Kota se Indonesia.

GEMMAR Mengaji adalah sebuah program untuk membudayakan membaca Al Qur`an setelah shalat Maghrib di 
kalangan masyarakat. Membaca $\mathrm{Al}$ Qur`an atau mengaji sejak dulu telah menjadi budaya masyarakat Indonesia. Namun akhir-akhir ini mengaji sudah mulai ditinggalkan. Masjid-Masjid kosong, tak ada lagi aktifitas pengajian. Umat lebih asyik di depan televisi, berkumpul, bergosip dan kesibukan lainnya daripada mengaji

a) Tujuan

Tujuan dari GEMMAR Mengaji ini adalah:

1. Menghidupkan kembali tradisi membaca / mendaras Al Qur`an setiap selesai shalat Maghrib di seluruh pelosok dan kampung-kampung/ komplek yang ada di Kecamatan Koto Tangah sehingga dengan begitu diharapkan masyarakat dapat memanfaatkan waktu antara Maghrib dan Isya dengan efektif untuk beribadah kepada Allah dan memperdalam wawasan keagamaannya dan tidak menghabiskan waktunya untuk hal-hal yang kurang bermanfaat.

2. Menumbuhkan kesadaran di tengahtengah masyarakat akan fungsi dan peranan Al Qur`an bagi kehidupan manusia sehingga Al Qur`an tetap dibaca dan dipelajari sekalipun telah tamat (khatam) dari Taman Pendidikan Al Qur`an

3. Meningkatkan minat dan kemampuan masyarakat dalam membaca $\mathrm{Al}$ Qur`an

4. Meminimalisir pengaruh negatif dari media elektronik

5. Mengimarahkan Masjid dengan gema ibadah
6. Meningkatkan kerjasama antara orang tua, masyarakat dengan unsur pendidikan dan pemerintah.

\section{b) Sasaran}

Sasaran dalam Gerakan Masayrakat Maghrib Mengaji (GEMMAR Mengaji) ini adalah seluruh komponen masyarakat yang ada di kampong-kampung khususnya di komplek Perumahan Singgalang Koto Tangah.

c) Strategi

Strategi yang dapat dilakukan untuk mensukseskan GEMMAR Mengaji ini antara lain:

1. Membuat regulasi tentang GEMMAR Mengaji

2. Meningkatkan kerja sama dengan unsur terkait

3. Memodifikasi sistem pembelajaran $\mathrm{Al}$ Qur’an

4. Mengaktifkan TPQ/SQ di Masjid

5. Memberikan reward bagi Masjid yang aktif

GEMMAR Mengaji seperti yang dilansir oleh wali kota bandung Ridwan Kamil (Khazanah, 30 Mei 2017, 19:26 WIB) mengatakan "saat ini, jumlah masjid yang ada di Kota Bandung kurang lebih berjumlah 4.000-an. Sedangkan yang mengikuti Maghrib Mengaji berjumlah 3.100 masjid. Dengan jumlah tersebut, mayoritas masjid di Kota Bandung melaksanakan Magrib mengaji. "Saya lagi bahagia, kenaikannya berdasarkan laporan dari Kesra. Jadi sebagai orang tua reugreug (tenang) anaknya jago ngaji dibanding diabur (dibiarkan) saja enggak jelas," kata dia. 
sejalan dengan pendapat Ridwan kamil untuk wilayah Bandung, pemuka Adat Mamk Sutoyo (Kepala Komplek, Wawancara sabtu, Januari 2018) Sumatera Barat mengatakan, "untuk meningkatkan motivasi kemesjid saja kami kewalahan, perlu adanya permen khusus atau perhatian pemerintah daerah untuk kegiatan ini. Dukungan pemerintah sangat dibutuhkan agar terlaksananya kegiatan ini”.

Dengan adanya kegiatan magrib mengaji adalah merupakan salah satu pembentukan mental spiritual warga dilakukan secara berbarengan. Dalam mensukseskan Gerakan Masyarakat Maghrib Mengaji, tokoh masyarakat mempunyai peran penting, antara lain sebagai berikut :

a) Menghimbau masyarakat untuk meramaikan Masjid di saat Maghrib secara khusus.

b) Membuat brosur yang isinya menyatakan untuk dapat kita melaksanakan shalat Maghrib dan mengaji di Masjid bersama-sama.

c) Memberikan ceramah kepada masyarakat melalui radio lokal untuk melaksanakan kegiatan Maghrib Mengaji.

d) Mensosialisasikan kepada masyarakat serta mengajak masyarakat untuk melaksanakan shalat di Masjid.

e) Mengevaluasi setiap Masjid yang ada, apakah mereka rutin melaksanakan Maghrib Mengaji.

f) Memberikan reward kepad

Masjid / masyaarakat mlaksanakan kegiatan thaharah Masjid. g) Memberikan dukungan terhadap pengurus Masjid baik secara moril maupun materil untuk melaksanakan kegitan Maghrib Mengaji.

h) Mengadakan pertemuan dengan masyarakat serta dinas / instansi terkait untuk mendukung pelaksanaan kegiatan Maghrib mengaji.

i) Bekerja sama dengan perusahaan yang ada di Kecamatan Koto Tangah untuk berperan serta dalam pelaksanaan Maghrib Mengaji.

j) Memfasilitasi berkembangnya TPQ / MDA di lingkungan komplek/ kampong-kampung

Mengaji Alquran sejak dulu telah menjadi budaya masyarakat Indonesia. Namun, akhir-akhir ini mengaji Alquran sudah mulai ditinggalkan. Umat Islam lebih asik mengikuti sinetron dan film seraya duduk berlama-lama di depan televisi dari pada membuka mushaf Alquran. Kementerian Agama (Kemenag) RI ingin mengembalikan tradisi mengaji setiap selesai shalat Maghrib dapat kembali dihidupkan di seluruh pelosok negeri. Masyarakat diajak untuk kembali membuka Alquran kendati mereka sudah khatam Alquran sebelumnya.

Dengan mengaji selepas shalat Maghrib, pengaruh-pengaruh negatif dari televisi dan media elektronik lainnya bisa diminimalisasi. Kementerian Agama (Kemenag) RI telah mencanangkan Gerakan Masyarakat Maghrib Mengaji atau yang lebih dikenal dengan GEMMAR Mengaji. GEMMAR Mengaji adalah sebuah program untuk membudayakan membaca Alquran setelah shalat Maghrib di kalangan masyarakat. 
Program GEMMAR Mengaji yang dicanangkan pemerintah melalui Kementerian Agama (Kemenag) RI telah berjalan sejak tahun 2011.

Namun dalam pengamatan peneliti, program Kementerian Agama (Kemenag) RI tersebut masih terfokus sasaran tertuju pada anak-anak saja. Sedangkan program mengaji Alquran kepada orang dewasa atau orang tua baik untuk bapak-bapaknya atau ibu-ibunya belum terlaksana dengan baik di masyarakat luas. Fenomena dilapangan banyak terlihat bagi orang tua mereka lebih memaksakan kepandaian mengaji kepada anak-anak mereka tanpa memperdulikan perhatian orang tua ataupun peran orang tua sebagai model anak-anak dirumah nantinya. survey membuktikan ada sekitar $80 \%$ orang tua belum lancer mengaji. (Dompet Duava DH, 7 July 2013)

http://ddhongkong.org/survei-65-persenmuslim-indonesia-tidak-bisa-baca-alquran/

Kegiatan mengaji untuk orang dewasa atau orang tua masih bersifat pada majlis taklim berupa mendengarkan ceramah agama ataupun pembacaan wirid yasin yang menjadi rutinitas mingguan. Kegiatan Wirid yasin yang peneliti amati di masyarakat sering dilakukan bapakbapak dan ibu-ibu setiap hari Kamis malam Jumat. Pada dasarnya masalah keinginan untuk belajar Alquran itu sangat didambakan oleh orang tua khususnya kaum ibu-ibu.

Akan tetapi sangat sedikit peluang mereka untuk dapat belajar Alquran, baik karena faktor usia atau karena kesibukan dalam mengurus rumah tangga mereka. Kadang kala dikarenakan tidak adanya lembaga atau mesjid di sekitar tempat tinggal mereka yang berupaya membuka program belajar Alquran. Sehingga mereka hanya mengikuti kegiatan keagamaan Islam apa adanya dalam mendekatkan diri kepada Allah SWT.

Didasarkan pengamatan peneliti juga, untuk daerah Kota khususnya di Kecamatan Area sangat minim sekali kegiatan belajar Alquran untuk kaum ibu/ bapak/ orang tua. Memang ada sebuah lembaga atau mesjid yang mengadakan belajar Alquran untuk kaum orang tua namun hanya di beberapa tempat saja. Kegiatan belajar mengaji Alquran untuk kaum ibu/ bapak/ orang tua ini hanya diminati oleh beberapa kaum ibu/ bapak/ orang tua saja yang tinggal dekat dengan mesjid. Akan tetapi belum bisa berbuat banyak untuk kaum ibu/ bapak. orang tuanya karena kegiatannya yang monoton.

Dari permasalahan di atas, Rumah Alquran RABBANI berusaha membuka peluang belajar Alquran untuk semua usia. Mulai dari anak-anak yang mempunyai dasar dapat mengenal huruf hijaiyah sampai orang tua yang ingin belajar Alquran. Sejalan dengan tujuannya semua bisa belajar Alquran. Khususnya kaum ibu yang ingin belajar Alquran dibukalah program belajar Alquran khusus kaum ibu. Hal ini juga sesuai dengan tujuan didirikannya yayasan tersebut menciptakan generasi Rabbani yang qurani

- Program pembelajaran Alquran khusus kaum ibu pun telah terlaksana mulai tahun 2012. Mempelajari Alquran merupakan suatu anjuran dalam agama Islam, karena Alquran adalah sebagai pedoman hidup umat manusia yang harus 
dipelajari. Dalam hal ini menjadi tolok ukur seorang muslim adalah sejauh mana upaya dan usahanya dalam mempelajari dan mengajarkan Alquran. Hal ini sesuai dengan Hadis Nabi SAW yang diriwayatkan oleh Imam at-Tirmidzi sebagai berikut:

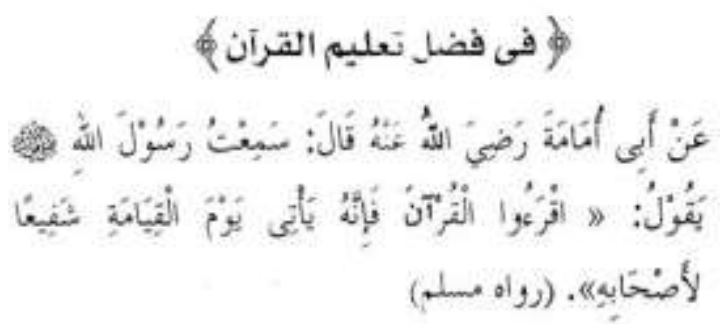

Artinya:

Dari Abi Umamah r.a. berkata, aku" mendengar Rasulullah Saw. bersabda: "Bacalah Ai-Qur'an, karena sesungguhnya Al-Qur'an itu pada hari Kiamat akan memberikan syafa'at kepada pembacanya.” (HR. Muslim)

Penjelasan:

Nabi Muhamad Saw. sangat mencintai ummatnya sehingga kita sebagai ummatnya dibimbing dan dihimbau agar mendapatkan pertolongan pada hari Kiamat. Siapa saja yang gemar membaca Al-Qur'an akan mendapat syafa'at dari AlQur'an yang pernah dibacanya di dunia.

Syafa'at artinya bantuan untuk menambal kekurangan, maksudnya apabila amal-amal ibadah yang kita kerjakan di alam dunia ini ternyata masih belum memadai untuk dapat menyelamatkan kita dari 'azab siksaan, maka bacaan AlQur'an akan menjadi penambah kekurangan tersebut.
Al-Qur'an adalah bacaan kaum muslimin, kitab suci ummat Islam dan petunjuk bagi manusia agar selamat dalam hidup di dunia. Oleh karena itu, setiap muslim wajib membacanya dengan penuh khusu' dan tadharru'.

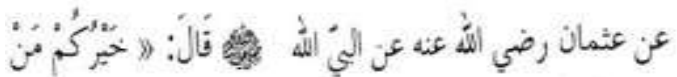

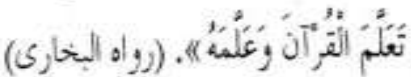

Hadits Tentang Keutamaan Mempelajari Al-Quran

Artinya:

Dari Usman bin Affan r.a. ia berkata, Rasullah Saw. bersabda: "orang terbaik dari kamu ialah orang yang mempelajari Al-Qur'an dan mengajarkannya". (HR al-Bukhari)

\section{Penjelasan:}

Kitab Al-Qur'an adalah petunjuk bagi orang-orang yang bertaqwa dan semua manusia dan penjelasan-penjelasan dari petunjuk itu. Maka tidak mungkin seorang muslim mampu membaca dan memahami kandungan isinya, melainkan harus mempelajarinya dengan sungguhsungguh.

Untuk itu, mempelajari Al-Qur'an, baik mengenai bacaanya secara benar sesuai dengan ilmu tajwid maupun mengkaji kandungan isinya hukumnya wajib bagi setiap pribadi seorang muslim.

Kewajiban seorang muslim terhadap islam (yang bersumber dari Al-Qur'an) sedikitnya ada 4 macam antara lain: 
1. Mempelajari peraturan dan hukumhukum islam.

2. Mengamalkan atau melaksanakan peraturan dan hukum-hukum islam.

3. Mengajarkan peraturan dan hukumhukum islam itu kepada orang lain! terutama kepada sesama muslim.

4. Menyi'arkan. ajaran Islam di tengahtengah masyarakat, (sehingga orang mengetahui bahwa di wilayah itu terdapat kaum muslimin.

Sampai saat ini, masih banyak umat islam yang tidak bisa membaca alqur'an dengan baik, apalagi memahami isinya. atas ketidakmampuan ini, mereka sering kali berdalih tidak mendapat pendidikan agama yang memadai pada waktu kecil. Firman Allah:

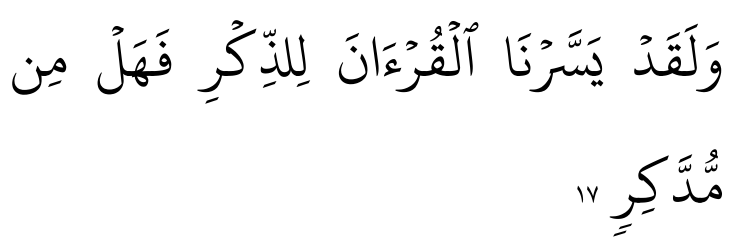

Artinya : "Dan sesunguhnya telah Kami mudahkan AIQur'an untuk pelajaran, maka adakah orang yang mengambil pelajaran" (Q.S. AI-Qamar (54): 17).

Bentuk kegiatan dalam Gemmar Mengaji yaitu:

a) Bentuk Pertama: Belajar Membaca dan Menulis Al-Qur'an Membangun keakraban dan kecintaan dengan alqur'an adalah berbicara tentang bagaimana cara mendekati al-qur'an. pendekatan ini akan gagal bila umat islam tidak mampu membaca al-qur'an secara baik dan benar. b) Bentuk kedua: Menghafal Surat-Surat PEndek (Juz A'mma) dan Mengkhatamkan Al-qur'an

1. mengafal surat-surat pendek

2. mengkhatamkan al-qur'an

c) Bentuk Ketiga: Belajar Memahami Arti Kata dan Terjemahan Al-qur'an pada bentuk ketiga ini yang harus dilalui, setelah umat islam mampu membaca al-qur'an dengan baik dan benar, maka bentuk pembelajaran mulai ditingkatkan pada pemahaman arti kata dan terjemahan al-qur'an

d) Bentuk Keempat: Belajar Memahami Tafsir Al-Qur'an pada bentuk ini, masyarakat muslim ditingkatkan kemampuannya, yaitu mulai belajar memahami tafsir alqur'an, di mulai tafsir yang sederhana (ringkas), sampai tafsir yang luas penjelasannya.

\section{METODE PENELITIAN DAN PEMBAHASAN}

\section{Jenis Penelitian}

Metode penelitian merupakan usaha penyelidikan yang sistematis dan terorganisasi. Arti sistematis dan terorganisasi menunjukkan bahwa untuk mencapai tujuan, maka penelitian dilakukan dengan cara-cara (prosedur) tertentu yang telah diatur dalam sebuah metode baku. Metode penelitian berisikan pengetahuan ketentuan metode-metode yang dipergunakan dalam langkahlangkah suatu proses penelitian

Waktu dan Tempat Penelitian 
Penelitian ini pada dasarnya adalah penelitian lapangan (field research), artinya penelitian dengan mengumpulkan data dari lapangan, menggambarkan dan menguraikan keadaan sebenarnya terjadi berdasarkan fakta yang disebut juga dengan penelitian kualitatif. Pada dasarnya pendekatan kualitatif adalah suatu pendekatan yang mengarah kepada keadaan yang secara utuh pokok kajiannya yang disederhanakan pada variabel yang telah ditata atau hipotesis yang telah direncanakan sebelumnya. Sehingga pendekatan ini diharapkan temuan-temuan empiris dapat dideskripsikan secara lebih rinci, lebih jelas dan lebih akurat. Sehingga menciptakan konsep yang baru dari konsep-konsep yang telah ada secara rasionalitas, dan dari pengamatan di lapangan dapat menganalisasinya dan berupaya melakukan teorisasi berdasarkan apa yang di amati.

\section{Subjek Penelitian}

Subjek penelitian dalam penelitian ini adalah Kecamatan Koto Tangah.

\section{Prosedur Penelitian}

Dalam penelitian kualitatif tidak menggunakan istilah populasi, tetapi oleh Spradley dinamakan "social situation" atau situasi sosial yang terdiri atas 3 elemen yaitu: tempat (place), pelaku (actor), dan aktifitas (actifity) yang berinteraksi secara sinergis.

Dari uraian Spradley ini, pelaku (actor) dapat dikatakan sebagai informan dalam penelitian ini. Informan dalam penelitian kualitatif dalam penelitian kualitatif ada yang disebut dengan informan awal, yakni orang yang pertama kali memberi informasi ketika peneliti melakukan penjajakan awal penelitian. Kemudian ada informan kunci, yakni orang yang bisa dikategorikan paling banyak mengetahui, menguasai informasi atau untuk menjawab permasalahan penelitian. Kemudian ada yang disebut dengan informan pangkal, yakni sebutan kepada orang yang pertama kali diwawancarai ketika peneliti melakukan teknik snowball (wawancara dari satu informan bergulir ke yang lain).

Adapun informan dalam penelitian ini adalah orang-orang yang dipilih, yang mana mereka bisa memberikan informasi yang akurat dan aktual, sehingga membantu proses penelitian ini, di antaranya:

1. Pembina Yayasan Rumah Alquran RABBANI

2. Ketua atau Mudir Yayasan Rumah Alquran RABBANI

3. Koordinator pengajian pembelajaran Alquran khusus kaum ibu di Rumah Alquran

4. Staf dan pengajar Yayasan Rumah Alquran RABBANI

5. Peserta atau jamaah Kaum Ibu yang aktif dalam pembelajaran Alquran

6. Pengurus (Ketua) Musholla yang menyelenggarakan kegiatan Magrib Mengaji

\section{PEMBAHASAN}

Penelitian ini juga mengumpulkan data dengan jalan mewawancarai ibu Azmarni selain sebagai jamaah pengajian 
Ibu-ibu beliau juga sebagai salah seorang Pembina Yayasan Rumah Alquran RABBANI. Ibu Azmarni mengatakan dengan senang sekali, ibu-ibu bisa belajar Alquran di Rumah Alquran. Ibu-ibu membaca Alquran ada yang memperbaiki bacaan supaya bagus huruf-hurufnya.

Ada yang belajar irama bacaan yang bagus dari ustadz yang mengajar di Rumah Alquran yang qari, seperti ustadz Firmansyah. Selanjutnya ibu-ibu yang belajar dapat mendengarkan penjelasan ayat yang dibaca dari Ustadznya. Komunikasi ini pun sangat interaktif di mana ibu-ibu yang belum faham dapat bertanya. Dan pembelajaran pun sangat bervariasi yang diakhiri dengan adanya kegiatan menghafal Alquran. Kegiatan menghafal Alquran dipimpin ibu Neni yang menjabat sebagai koordinator jamaah pngajian pembelajaran Alquran khusus kaum ibu-ibu.

Ibu Azmarni juga mengatakan bahwa semua ibu-ibu diamanahi rasa dan memiliki tanggung jawab bersama di Yayasan Rumah Alquran RABBANI. Semua yang belajar mengaji, secara pribadi beliau akan mengusahakan agar pengajian ini berkembang dan semakin besar. Maka ibu Azmarni sering mengajak ibu-ibu yang dikenalnya, baik tetangganya, kawan-kawannya, maupun ibu-ibu di jamaah pengajian yang ibu Azmarni ikuti supaya ikut belajar Alquran di Rumah Alquran RABBANI.

Hasilnya sebagian besar mau ikut mengaji di Rumah Alquran RABBANI. wawancara selanjutnya dilakukan kepada ibu Neni Liswani, sebagai koordinator pengajian pembelajaran Alquran khusus kaum ibu di Rumah Alquran RABBANI.
Beliau mengatakan bahwasanya ibu-ibu senang dengan adanya Rumah Alquran RABBANI yang membuka program belajar untuk orang tua juga. Karena sepengetahuan ibu-ibu itu belum ada yang berbuat seperti program belajar Alqur'an khusus untuk kaum ibu selain Rumah Alquran RABBANI. Di tempat lain yang ibu-ibu itu ketahui hanya pengajian biasa khusus mendengarkan ceramah dari ustadznya. Dan kalupun ada hanya berbentuk pengajian perwiridan yang hanya sebagai rutinitas mingguan, dan yang dibaca hanya terfokus pada bacaan surat Yaasin.

Ibu Neni Liswani juga mengatakan bahwa rumah Alquran ini dijadikan tempat menyatukan yang selalu berjarak karena perbedaan pemahaman. Dengan menyampaikan semua ibu-ibu yang hadir belajar di Rumah Alquran hanya satu tujuan, yakni belajar Alquran. Karena Alquran itu kitab suci semua umat Islam yang tidak ada perbedaan dalam tulisan isinya. Alquran berasal dari Nabi yang sama yakni Nabi Muhammad SAW.

Serta tujun semua yang hadir hanyalah membuka pola fikir ibu-ibu supaya beribadah yang baik juga sesuai tuntunan Rasulullah SAW. Ibu Siti Aisyah informan wawancara selanjutnya adalah salah seorang jamaah pengajian pembelajaran Alquran di Rumah Alquran RABBANI. Beliau mengatakan belajar Alquran di Rumah Alquran RABBANI menimbulkan semangat belajar.

Disamping menambah ilmu juga menambah persaudaraan yang mendapatkan kawan banyak. Meskipun Ibu Siti Aisyah rumahnya jauh dari Rumah Alquran RABBANI, tetap merasa 
malu jika tidak hadir. Karena ibu-ibu yang datang belajar ke Rumah Alquran RABBANI ada yang datang lebih jauh dari rumahnya.

Ada ibu-ibu yang datang dari Jati, Lubuk Buaya, dan tempat lainnya namun mereka tetap mau ikut belajar. Ibu-ibu semangat datang dan merasa rugi seandainya jika datang tidak membaca ayat Alquran. Ibu-ibu ingin agar bacaanya dapat didengar oleh ustadzt dan dapat diketahui dan diperbaiki mana yang harus dibaguskan bacaannya oleh ustadzt yang mengajar.

Dari hasil wawancara tersebut di atas, bahwa Pimpinan Yayasan Rumah Alquran RABBANI dalam menetukan suatu tujuan organsasinya melibatkan semua unsur pimpinan untuk dikomunikasikan dalam setiap program. Seperti Ketua Yayasan selalu berkoodinasi dengan Ketua Pembina Yayasan Rumah Alquran RABBANI. Pimpinan yayasan juga sangat terbuka kepada semua jamaah, khususnya dalam permasalahn ini kaum ibunya yang sangat dihargai dari setiap ide dan saransarannya. Sehingga semua ibu-ibu bisa memberikan gagasan-gagasan dan ide-ide dalam penetuan suatu tujuan Yayasan Rumah Alquran RABBANI.

Tujuannya adalah dalam meningkatkan dan memotivasi kaum ibu senantiasa semangat belajar Alquran di Yayasan Rumah Alquran RABBANI Dalam mengetahui program pembelajaran Alquran yang dikembangkan oleh Yayasan Rumah Alquran RABBANI program ini diterima dan diikuti oleh jamaah ibu-ibu. Bahkan dalam menambah ilmu membaca Alquran dengan membuka program yang sama di tempat ibu-ibu itu berdomisili. Seperti di Musholla Amal di Jalan Sutrisno Gang Aman, Ketua Musholla Amal itu sendiri menyatakan sangat mendukung program Rumah Alquran RABBANI. Karena yang dipelajari adalah pedoman kitab suci umat Islam.

Hal ini peneliti jika mengaitkan dengan teori dalam komunikasi oleh $\mathrm{Karl}$ Weick, sebagai penggagas teori informasi komunikasi menyatakan bahwa teori informasi organisasi memiliki kedudukan penting dalam ilmu komunikasi karena menggunakan komunikasi sebagi dasar atau basis bagaimana mengatur atau mengorganisasi manusia dan memberikan pemikiran rasional dalam memahami bagaimana manusia berorganisasi.

Menurut teori ini, organisasi bukanlah struktur yang terdiri atas sejumlah posisi atau peran, tetapi merupakan kegiatan komunikasi sehingga sebutan yang lebih tepat sebenarnya adalah organizing atau mengorganisasi (yang menunjukkan proses) daripada organization atau organisasi, karena organisasi adalah sesuatu yang ingin dicapai melalui proses komunikasi yang berkelanjutan.

Satu cara lain untuk melihat struktur organisasi adalah dengan meneliti polapola interaksi dalam organisasi guna mengetahui siapa berkomunikasi dengan siapa. Karena tidak seorangpun mampu berkomunikasi secara persis sama dengan setiap anggota organisasi lainnya, maka kita dapat melihat kelompokkelompok komunikasi yang saling berhubungan sama lain sehingga membentuk jaringan organisasi secara keseluruhan. Hal ini 
merupakan gagasan dari Peter R. Monge dan Noshir S.

Contractor mengenai teori jaringan. Menurut hasil penelitian, Strategi komunikasi Pimpinan Yayasan Rumah Alquran RABBANI dalam Penentuan Tujuan Komunikasi adalah sebagai berikut:

Pertama dalam menentukan tujuan komunikasi Pimpinan Yayasan Rumah Alquran RABBANI sangat melibatkan semua unsur dari Yayasan sebagai informasi program kegiatan. Menerima saran dan masukan dari jamaah kaum ibu dalam pengembangan dan kebersamaan semangat belajar Alquran dalam menetukan tujan komunikasi. Kedua, Pimpinan Yayasan Rumah Alquran RABBANI dalam menentukan tujuan komunikasi juga menanamkan rasa tanggung jawab bagi ibuibu.

Ibu-ibu yang mengikuti program pembelajaran bertanggung jawab untuk menyebarkan informasi kepada masyarakat khususnya kaum ibu-ibu untuk ikut serta dalam program pembelajaran Alquran khusus kaum ibu di Rumah Alquran RABBANI. Sehingga dalam menentukan tujuan komunikasi yang diharapkan berjalan sebagaimana mestinya

\section{KESIMPULAN DAN SARAN}

1. Kesimpulan

Gerakan Masyarakat Maghrib Mengaji adalah sebuah program untuk membiasakan masyarakat membaca $\mathrm{Al}$ Qur`an atau mengaji setelah selesai shalat Maghrib daripada masyarakat lebih banyak menghabiskan waktunya di depan televisi di waktu Maghrib sehingga terlupa akan waktu Maghrib yang sangat singkat.

2. Saran

Diharapkan kepada seluruh komponen masyarakat untuk menggalakkan Gerakan Masyarakat Maghrib Mengaji ini di wilayahnya masing-masing sehingga Gerakan yang telah dicanangkankan ini dapat dilaksanakan oleh masyarakat untuk seterusnya.

\section{DAFTAR RUJUKAN}

http://www.agamkab.go.id/?agam=geloraagam \&se=maghrib-mengaji

http://khazanah.republika.co.id/berita/duni a-islam/islamnusantara/17/05/30/oqrmjn361capaian-program-magrib-mengajimeningkat-hingga-3100-masjid

http://www.republika.co.id/berita/koran/di alog-jumat/14/06/06/n6qgo72-profdrnasaruddin-umar-mengembalikanbudaya-mengaji-umat-islam, diakses pada tanggal 23 Juli 2015.

http://www.jurnalasia.com/nasional/pemk ab-solok-sosialisasi-programmaghrib-mengaji/

Keputusan Menteri Agama RI no. 150 Tahun 2013 tentang Pedoman Grakan Masyaraakt Maghrib Mengaji.

A.M., Sardiman. Interaksi dan Motivasi Belajar Mengajar. Jakarta: PT. RajaGrafindo Persada. 2007. 
Al-Hjazy, Hasan bin Ali. Manhaj Tarbiyah Ibnu Qayyim. Terj. Muzadi Hasbullah. Jakarta: Pustaka Al-Kautsar. 2001.

Ar-Raniry, Manajemen PT. Arun \& Dosen IAIN. Pernik-Pernik Manajemen Qur'ani. Aceh Utara: Humas PT. Arun NGL. Co. 1996.

As-Sirjani, Raghib. Mukzizat Menghafat Alquran. Terj. Buldan T.M. Fatah. Jakarta: Zikrul Hakim. 2009)

http://ddhongkong.org/survei-65-persenmuslim-indonesia-tidak-bisa-bacaal-quran 